\title{
Characterization and Comparison of Unfermented and Fermented Seed-Watermelon Juice
}

\author{
Jing Wang, ${ }^{1,2}$ Yue Shi, ${ }^{1,3}$ Huijuan Zhang, ${ }^{2}$ Xingxing Deng, ${ }^{1,4}$ Yubin Wang,,3 \\ Yue Ma, ${ }^{3,5}$ Xiaoyan Zhao, ${ }^{1,5}$ and Chao Zhang $\mathbb{D}^{1,2,3}$ \\ ${ }^{1}$ Beijing Academy of Agriculture and Forestry Sciences, Beijing Vegetable Research Center, Beijing 100097, China \\ ${ }^{2}$ Beijing Advanced Innovation Center for Food Nutrition and Human Health, \\ Beijing Technology and Business University (BTBU), Beijing 100048, China \\ ${ }^{3}$ Beijing Key Laboratory of Fruits and Vegetable Storage and Processing, Beijing 100097, China \\ ${ }^{4}$ Key Laboratory of Biology and Genetic Improvement of Horticultural Crops (North China) of Ministry of Agriculture, \\ Beijing 100097, China \\ ${ }^{5}$ Key Laboratory of Vegetable Postharvest Processing of Ministry of Agriculture, Beijing 100097, China
}

Correspondence should be addressed to Chao Zhang; zhangchao@nercv.org

Received 24 May 2018; Revised 25 July 2018; Accepted 19 August 2018; Published 29 October 2018

Academic Editor: Ekaterini Moschopoulou

Copyright $(2018$ Jing Wang et al. This is an open access article distributed under the Creative Commons Attribution License, which permits unrestricted use, distribution, and reproduction in any medium, provided the original work is properly cited.

\begin{abstract}
Fermented juice was prepared with byproducts (pulp and rind) of seed watermelon (Citrullus lanatus sp. vulgaris var. megalaspermus) for the first time, and its radical scavenging capacity and aroma were compared with those of the corresponding unfermented juice. The 2,2-diphenyl-1-picryhydrazyl and hydroxyl radical scavenging capacities of the fermented juice were significantly stronger than those of the unfermented juice. The oxygen radical scavenging capacity of the fermented juice was $60 \mu \mathrm{M}$ trolox equivalent $/ \mathrm{mL}$, which was $7.14 \%$ higher than that of the unfermented juice. Gas chromatography-mass spectrometer analysis showed a total of 26 and 29 volatiles in unfermented juice and fermented juice, respectively. The content of typical watermelon aroma, including 1-nonanol, 3,6-nonadien-1-ol, nonanal, trans-2-nonenal, and trans,cis-2,6-nonadienal, was reduced from $92.08 \mathrm{mg} / \mathrm{L}$ in the unfermented juice to $26.41 \mathrm{mg} / \mathrm{L}$ in the fermented juice. Furthermore, isoamylol, ethyl octanoate, ethyl acetate, and ethyl laurate contributed a typical grape-wine bouquet to the fermented juice. Sensory evaluation further confirmed the attractive appearance and watermelon aroma of the fermented juice. Therefore, the fermented seed-watermelon juice showed a strong radical scavenging capacity and presented the typical watermelon aroma with a grapewine bouquet.
\end{abstract}

\section{Introduction}

Watermelon juice is welcomed for its aroma and health for most people. Consumption of watermelon juice protects the chemical-induced hepatotoxicity in rats [1], increases plasma concentrations of $\beta$-carotene in humans [2], and increases antiproliferative activity on both human breast and liver cancer cell lines [3]. Seed watermelon (Citrullus lanatus $\mathrm{sp}$. vulgaris var. megalaspermus) is the same species with watermelon in Cucurbitaceae but cultivated for seed. Byproducts (pulp and rind) of seed watermelon constituting about $90 \%$ of fruit weight are directly thrown in the fields [4].
The byproducts are rich in polyphenol, sugar, and some other biological-related compounds and present a strong radical scavenging capacity $[5,6]$. However, a further application of the byproducts has not been reported.

Fermentation is a traditional way to preserve high sugar and high moisture products. Grape wine is one of the successful examples. Fermentation of wine reduces price fluctuations and enhances the economic benefit of the fruits [7]. Moreover, fermentation raises the radical scavenging capacity of red grape wine [8] and pomegranate wine as well [9] and maintains the typical aroma of grape or rice in their corresponding fermented products $[10,11]$. Consequently, 
for the first time, the byproducts of seed watermelons were used to prepare the fermented juice. Our previous results proved that the wine active dry yeast (RV100, E80001478, Angel Yeast Co., Ltd., Yichang, China) maintains the typical watermelon aroma of the fermented juice [12]. However, the radical scavenging capacity and aroma composition of the unfermented juice and fermented juice were neglected. Hence, both unfermented juice and fermented juice were prepared and their characteristics were compared.

\section{Material and Methods}

2.1. Preparation of Unfermented and Fermented Juice. Mature seed watermelons (Citrullus lanatus sp. vulgaris var. megalaspermus) were harvested in September 2015 in Beijing Sijiqing Farm. The fruits were round with regular green stripes and an average weight of $2.3 \mathrm{~kg}$. The pulp was light yellow and full of black seeds. The thickness of the rind was $8 \sim 12 \mathrm{~mm}$. After stored at $4^{\circ} \mathrm{C}$ for $24 \mathrm{~h}$, the cold fruits were washed in $100 \mathrm{ppm}$ ice sodium hypochlorite solution and blanched in $50 \mathrm{ppm}$ ice sodium hypochlorite solution in a clean workshop. The washed fruits were drained in a big case for $30 \mathrm{~min}$. The drained fruits were then cut into blocks (enabling access to the juicer), and the blocks were dropped into a juicer (Philips HR1876, Philips, Dongguan, China). The juicer removed the seeds while collecting the juice. The juice was nominated as the unfermented juice. The soluble solid content and $\mathrm{pH}$ of the juice were adjusted to $20^{\circ} \mathrm{Brix}$ by adding sucrose and $\mathrm{pH} 5.5$ by adding $0.5 \mathrm{M} / \mathrm{L}$ sodium bicarbonate solution, respectively. The resulting juice was inoculated with the activated yeast mixture at $0.2 \%(\mathrm{v} / \mathrm{v})$. The activated yeast mixture was prepared by blending the dry yeast (Wine active dry yeast RV100, E80001478, Angel Yeast Co., Ltd, ) of $500 \mathrm{~g}$ and $10 \mathrm{~L}$ of the sucrose solution $(5 \%, \mathrm{w} / \mathrm{v})$ at $30^{\circ} \mathrm{C}$ for about $1 \mathrm{~h}$. The inoculated juice was covered by gauze and stored at $25^{\circ} \mathrm{C}$ for $15 \mathrm{~d}$ and then filtered via 4-layer gauze. The resulting juice was stored at $25^{\circ} \mathrm{C}$ for $90 \mathrm{~d}$ for further analysis, which was nominated as the fermented juice.

2.2. Determination of Phenolic Content. The phenolic content was measured via the Folin-Ciocalteu reagent method with gallic acid as a reference [13]. In brief, the sample of $25 \mathrm{~g}$ was blended with $50 \mathrm{~mL}$ cold $80 \%$ acetone for $5 \mathrm{~min}$ via a magnetic blender. The mixture was filtered through Whatman \#1 paper. The paper was rinsed by $10 \mathrm{~mL}$ cold $80 \%$ acetone for two times. All permeate was collected and evaporated to $<10 \%$ initial weight at $45^{\circ} \mathrm{C}$ with a rotary evaporator (Buchi Vacuum Rotavapor R215, Buchi Labortechnik AG, Flawil, Switzerland). The extract was diluted to $25 \mathrm{~mL}$ with $70 \%$ methanol and stored at $-40^{\circ} \mathrm{C}$ until further measurement. The measurement mixture contained $50 \mu \mathrm{L}$ of the methanol extract, $250 \mu \mathrm{L}$ of Folin-Ciocalteu reagent, $0.75 \mathrm{~mL}$ of $20 \%$ sodium carbonate, and $3 \mathrm{~mL}$ of deionized water. After inoculation at $25^{\circ} \mathrm{C}$ for $2 \mathrm{~h}$, the absorbance at $765 \mathrm{~nm}$ was measured with the reaction mixture without sample as control via an ultraviolet spectrophotometer (UV1800, Shimadzu Corporation, Kyoto, Japan). The result was determined from the linear calibration curve and was expressed as mg gallic acid equivalent/L.

2.3. DPPH Radical Scavenging Capacity. The free radical scavenging capacity was evaluated using 2,2-diphenyl-1picryhydrazyl (DPPH) radical method [14]. Sample solutions $(1.0 \mathrm{~mL})$ were mixed with $4.0 \mathrm{~mL}$ DPPH solution $(125 \mu \mathrm{M})$. The mixture was shaken vigorously and incubated in the dark at $25^{\circ} \mathrm{C}$ for $60 \mathrm{~min}$. The absorbance of the resulting mixture was measured on an ultraviolet spectrophotometer (UV-1800, Shimadzu Corporation, Kyoto, Japan) at $515 \mathrm{~nm}$ after incubation at $30^{\circ} \mathrm{C}$ for $1 \mathrm{~h}$ with butylated hydroxytoluene $(\mathrm{BHT})$ as the control. The $\mathrm{DPPH}$ radical scavenging activity was calculated as a percentage of $\mathrm{DPPH}$ discoloration as BHT equivalent.

2.4. Hydroxyl Radical Scavenging Capacity. The hydroxyl radical scavenging capacity was examined based on Fenton reaction, whereas 5,5-dimethyl- $N$-oxide pyrroline (DMPO) was used as the trapping agent [15]. The reaction mixture contained $10 \mu \mathrm{L}$ of $3 \mathrm{mM}$ freshly prepared $\mathrm{FeSO}_{4}, 80 \mu \mathrm{L}$ of $0.75 \mathrm{mM}$ PBS, $15 \mu \mathrm{L}$ of $10 \mathrm{mM} \mathrm{H}_{2} \mathrm{O}_{2}, 15 \mu \mathrm{L}$ of $1 \mathrm{M}$ DMPO, and $30 \mu \mathrm{L}$ of sample or solvents for the blank. The reaction mixture was evenly shaken and incubated for $60 \mathrm{~min}$ at $37^{\circ} \mathrm{C}$. The absorbance of the resulting mixture was measured at $510 \mathrm{~nm}$ via an ultraviolet spectrophotometer (UV-1800, Shimadzu Corporation, Kyoto, Japan). The scavenging capacity of hydroxyl radical was calculated as (1 - absorbance of sample/absorbance of control) $\times 100 \%$.

The scavenging activity of the sample was further expressed as IC50. Specifically, the sample was diluted to $1 \%$, $5 \%, 10 \%, 25 \%, 50 \%, 75 \%$, and $100 \%$ in deionized water. The scavenging activity of the sample dilution was measured and exponentially fitted. The IC50 of the sample was calculated based on the exponentially fitted curves.

2.5. ORAC Assay. The oxygen radical absorbance capacity (ORAC) of the sample was measured according to the recently reported protocol $[16,17]$. The sample was measured in a hydrophilic system. Specifically, the sample $(20 \mu \mathrm{L})$ was pipetted to the proper well and incubated for $10 \mathrm{~min}$ with fluorescein as the fluorescent probe. The final assay solution contained $0.067 \mu \mathrm{M}$ of fluorescein, $60 \mathrm{mM}$ of $2,2^{\prime}$-azobis-2methyl-propanimidamide, $300 \mu \mathrm{L}$ of sample, or $7 \% \beta$-cyclodextrin as a reagent blank. The fluorescence of an assay mixture was measured and recorded once every minute. The trolox equivalent (TE) was calculated using a standard curve prepared with trolox and used to compare the ORAC of various samples via expression as $\mu \mathrm{M} \mathrm{TE} / \mathrm{g}$.

The fermented juice without ethanol was measured to show the contribution of ethanol to the oxygen radical scavenging capacity. Specifically, the fermented juice was concentrated to about $10 \%$ of the original volume via nitrogen blowing at $25^{\circ} \mathrm{C}$. The resulting solution was diluted to its original volume by adding deionized water. The ORAC of the diluted solution was measured. 
2.6. Determination, Quantification, and Classification of Volatiles. An aliquot of $2 \mathrm{~mL}$ of the sample was put into a $20 \mathrm{~mL}$ glass vessel. The glass vessel was placed in a water bath at $50^{\circ} \mathrm{C}$ for $30 \mathrm{~min}$. The headspace was purged with a constant flow of nitrogen at $20 \mathrm{~mL} / \mathrm{min}$ for $10 \mathrm{~min}$. The volatile compounds were trapped in a glass capillary tube ( $3 \mathrm{~mm}$ internal diameter) containing $100 \mathrm{mg}$ of Tenax ${ }^{\circledR}$ adsorbent. The Tenax ${ }^{\circledR}$ trap was then disconnected from the system and placed in a Chrompack TCT/PTI 400 injector.

The volatiles were evaluated on an Agilent 6890 gas chromatograph coupled to an Agilent 5973I mass selective detector (Agilent Technologies, Palo Alto, CA). The volatiles were separated on a DB-WAX column $(30 \mathrm{~m} \times 0.25 \mathrm{~mm}$ i.d., $0.25 \mu \mathrm{m}$ film thickness, Agilent Technologies). The injection was performed in splitless mode $(0.7 \mathrm{~mm}$ splitless inlet liner, Supelco), and the injector temperature was $250^{\circ} \mathrm{C}$. The purge valve was opened at $0.5 \mathrm{~min}$ at a $50 \mathrm{~mL} / \mathrm{min}$ flow rate. Helium (99.999\%) was used as a carrier gas with a constant starting flow rate at $1 \mathrm{~mL} / \mathrm{min}$. The oven temperature was programmed as follows: $45^{\circ} \mathrm{C}$ for $3 \mathrm{~min}$, $5^{\circ} \mathrm{C} / \mathrm{min}$ to $120^{\circ} \mathrm{C}$, and $10^{\circ} \mathrm{C} / \mathrm{min}$ to a final temperature of $200^{\circ} \mathrm{C}$ with a final holding time of $5 \mathrm{~min}$. The detector was fitted with an electron impact ionization source set at $200^{\circ} \mathrm{C}$. The quadrupole temperature was set to $150^{\circ} \mathrm{C}$, and the transfer line temperature was kept at $250^{\circ} \mathrm{C}$. The solvent delay was set to $3 \mathrm{~min}$. Total ion chromatograms were collected scanning from $\mathrm{m} / \mathrm{z} 35$ to 500 at a rate of 3.06 scans/s.

Volatiles were identified via comparison of their mass spectra and retention times to those of authentic standards or via comparison of Kovats' retention indexes and mass spectrum to those reported in the NIST Mass Spectral Search Program (version 2.0a) with $<80 \%$ as a cutoff to match compounds.

Quantification of the volatile compounds was conducted via calibration curves in the selected ion monitoring mode. The 2-methyl-3-heptanone with a concentration of $45 \mathrm{mg} / \mathrm{L}$ in the analyzed samples was used as internal standard to monitor instrument response and retention time stability. Quantitative analysis was performed using software Agilent MassHunter (USA).

The volatiles were classified via their chemical structure and aroma style. Specifically, the chemical structure included alkane, alcohol, aldehyde, ketone, acid, and ester. The aroma style included flower, fruit, grass, fragrant, oil, and bouquet based on the manual Perfumes [18].

2.7. Sensory Evaluation. A panel of 12 judges was composed of seven males and five females between the ages of 22 and 55 years. Each judge was an experienced wine taster, and eight of them were employees of our institution. The panel had already been trained to assess wines using the quantitative descriptive analysis technique for previous projects. However, the panel attended an additional four-hour training session to ensure reliability and accuracy of the data. The panel was trained in both definition and recognition of appearance, flavor, sweetness, acidity, hotness, viscosity, and aroma and the use of nine-point scales. The aim of the evaluation and definitions of rating items were clearly explained.

The sensory evaluation was performed between 10 a.m. and 12 a.m. with three rounds over three weeks. In each round, three cups of unfermented juice $(30 \mathrm{~mL})$ and three cups $(30 \mathrm{~mL})$ of fermented juice were served in randomized order for all judges in ISO wine tasting glasses in tasting booths at $25^{\circ} \mathrm{C}$. Remarkably, the unfermented juice was prepared just prior to each round and served at $18^{\circ} \mathrm{C}$. Each bottle of the fermented juice was opened just prior to each round and served at $18^{\circ} \mathrm{C}$. The judges rated the intensity of appearance, flavor, sweetness, acidity, hotness, viscosity, and aroma using a nine-point scale. For the appearance, flavor, hotness, sweetness, and viscosity attributes, these were light, light-medium, medium, medium-full, and full in a ninepoint scale. For all other attributes, the word anchors describing intensity were low, low-medium, medium, medium high, and high in a nine-point scale. The judges rated the items with a cross in the scale. This protocol was repeated for three times over three weeks. The result was the average of the three rounds.

2.8. Statistical Analysis. The data were expressed as average \pm standard deviation of at least three repetitions. Analysis of variance was used to compare mean differences of the results. If differences among means were detected, multiple comparisons were performed using Duncan's multiple range test. Directional difference tests were employed to enable direct comparison of the results of the sensory evaluations. All analyses were conducted in SPSS (Windows Version 19).

\section{Results and Discussions}

3.1. Characterization of Unfermented and Fermented SeedWatermelon Juice. The characterization of both unfermented and fermented juice of seed watermelon is listed in Table 1. Soluble solid content and sugar-to-acid ratio are generally taken as a basic characteristic of juice quality, which show good relationships with consumer acceptability [19]. USDA defines the sugar-to-acid ratio between 12 and 20 as the standard of level A of orange juice [20], which means a higher consumer acceptability of the juice. The soluble solid content and sugar-to-acid ratio of the fermented juice were $(5.20 \pm 0.1){ }^{\circ}$ Brix and (12.4 \pm 0.5$)$, respectively. The sugar-to-acid ratio of the fermented juice was laid in the range of level A of orange juice. However, the soluble solid content and sugar-to-acid ratio of the unfermented juice were $(2.3 \pm 0.1){ }^{\circ}$ Brix and $(23.9 \pm 0.6)$, respectively. Consequently, the unfermented juice was plain and unbalanced. Compared to the unfermented juice, the fermented juice was more balance with a light sweetness.

The phenolic content of the fermented juice was significantly higher than that of the unfermented juice. Similar results were also reported for cherry wine [21] and grape wine [22], where the phenolic content is raised after fermentation. This phenomenon could result from the degradation of hydrolytic tannin and condensed tannin during fermentation [23]. 
3.2. Radical Scavenging Capacities of Unfermented and Fermented Seed-Watermelon Juice. The DPPH radical is usually defined as chemically relevant radicals. Consequently, the DPPH radical has been used to assess the ability of phenolic compounds to transfer labile $\mathrm{H}$ atoms to the radical, which is linearly related to the phenolic content [24]. Fermentation significantly raises the DPPH radical scavenging capacity of red grape wine [8] and raises the hydroxyl radical scavenging capacity of pomegranate wine as well [9]. The radical scavenging capacities of unfermented and fermented juice were explored (Table 1). The DPPH scavenging capacities of the unfermented and fermented juice were $(41.5 \% \pm 1.8)$ and $(45.4 \% \pm 0.9)$, respectively. The DPPH scavenging capacity of the fermented juice was significantly higher than that of the unfermented juice. Remarkably, the DPPH radical scavenging capacity of the fermented juice was higher than that of coconut wine (25.6\%) [25] but was lower than that of red grape wine (60\% 70\%) [8]. Furthermore, the DPPH radical scavenging capacities of the unfermented and fermented juice were further converted to $(0.513 \pm 0.011)$ and $(0.592 \pm$ 0.014) $\mathrm{mg}$ BHT equivalent $/ \mathrm{mL}$, respectively. This result indicated that the intake of $100 \mathrm{~mL}$ unfermented or fermented juice was equivalent to the intake of BHT of 51.3 or $59.2 \mathrm{mg}$, respectively.

Hydroxyl and oxygen radicals belong to reactive oxygen species, which are the main reasons leading to an oxidative stress and thereby chronic diseases such as heart disease, cancer, diabetes, and Alzheimer's disease [26-28]. Hence, both hydroxyl and oxygen radicals are usually defined as the biologically relevant radicals. The IC50 of hydroxyl radical scavenging capacities of the fermented juice was $14.6 \pm$ $0.56 \%$, which was significantly lower than that of the unfermented juice of $28.1 \pm 1.02 \%$. Hence, the fermented juice was more effective to scavenge hydroxyl radicals than the unfermented juice.

The ORAC values of the unfermented juice, fermented juice, and fermented juice without ethanol were 56, 60, and $59 \mu \mathrm{M} \mathrm{E} / \mathrm{g}$, respectively. The fermented juice with or without ethanol presented a stronger oxygen radical scavenging capacity than the unfermented juice. The ORAC value of the fermented juice was about $7.14 \%$ higher than that of the unfermented juice. The results were in good agreement with the higher total phenol content of the fermented juice. Moreover, the ORAC value of the fermented juice was higher than that of the fermented juice without ethanol due to the contribution of ethanol [29]. The ethanol in the fermented juice contributed the ORAC value of $1.6 \%$. Furthermore, the ORAC value of our products is comparable to that of other wines and fruits (Table 2). The ORAC value of the fermented juice was higher than that of coconut wine $(27.9 \mu \mathrm{M} \mathrm{TE} / \mathrm{g})$ [25]. The ORAC values of both unfermented and fermented juice were higher than that of muskmelon, carrot, and tomato but lower than that of blueberry, apple, avocado, and broccoli [16].

In summary, the radical scavenging capacities of the fermented juice were stronger than that of the unfermented juice for both chemical and biologically relevant radicals.
TABLE 1: Characterization of the unfermented and fermented juice.

\begin{tabular}{lcc}
\hline Items & $\begin{array}{c}\text { Unfermented } \\
\text { juice }\end{array}$ & $\begin{array}{c}\text { Fermented } \\
\text { juice }\end{array}$ \\
\hline Titratable acid content (based on & $0.0963 \pm$ & $0.420 \pm$ \\
citrate acid) $(\mathrm{g} / 100 \mathrm{~mL})$ & 0.0005 & $0.006^{*}$ \\
Soluble solid content $\left({ }^{\circ}\right.$ Brix) & $2.3 \pm 0.1$ & $5.20 \pm 0.1^{*}$ \\
Ratio of sugar to acid & $23.9 \pm 0.6$ & $12.4 \pm 0.5^{*}$ \\
Alcohol content (v/v) & - & $7.60 \pm 0.13$ \\
pH & $4.83 \pm 0.02$ & $3.54 \pm$ \\
Phenolic content $(\mathrm{mg} / \mathrm{L})$ & $37.6 \pm 0.58$ & $41.2 \pm 0.67^{*}$ \\
DPPH scavenging capacity (\%) & $41.5 \pm 1.8$ & $45.4 \pm 0.9^{*}$ \\
DPPH scavenging capacity (mg & $0.513 \pm 0.011$ & $0.592 \pm$ \\
BHT equivalent/mL) & & $0.014^{*}$ \\
IC50 of hydroxyl radical (\%, the & $28.1 \pm 1.02$ & $14.6 \pm$ \\
sample in deionized water) & & $0.56^{*}$ \\
\hline
\end{tabular}

${ }^{*}$ A significant difference with data in the same line $(p<0.05)$.

TABLE 2: ORAC values of some fruits.

\begin{tabular}{lc}
\hline Item & ORAC $(\mu \mathrm{M} \mathrm{TE} / \mathrm{g})$ \\
\hline Blueberry & 469 \\
Apple & 149 \\
Avocado & 86 \\
Broccoli & 168 \\
Muskmelon & 45 \\
Carrot & 25 \\
Tomato & 53 \\
Unfermented juice & 56 \\
Fermented juice & 60 \\
Fermented juice without ethanol & 59 \\
\hline
\end{tabular}

3.3. Volatiles of Unfermented and Fermented SeedWatermelon Juice. Volatiles of both unfermented and fermented juice were analyzed via GC-MS analysis. The total ion chromatography of the unfermented and fermented juice is shown in Figure 1. The peak presented at $4.2 \mathrm{~min}$ in the total ion chromatography profile of the fermented juice was assigned to ethanol, which constituted $6.3 \%$ of the total area. The ethanol content of $0.5 \% \sim 0.75 \%$ raises the fruity character of the aroma, while a higher content does not [30]. Hence, the contribution of ethanol to aroma of the fermented juice was ignored in the following analysis.

Table 3 shows the assigned volatiles of both unfermented and fermented seed-watermelon juice. A total of 26 volatiles were assigned in the unfermented juice with hexanol, 1nonanol, 3-hexen-1-ol, trans,cis-2,6-nonadienal, trans-2nonenal, and nonanal as main components. Among the main components, the $\mathrm{C} 9$ alcohol and aldehyde, including 1nonanol, nonanal, trans,cis-2,6-nonadienal, and trans-2nonenal, formed the typical watermelon aroma [27, 31-34]; C5 C7 alcohol and aldehyde usually show aroma of fruits; C10 C13 alcohol and aldehyde show the aroma of the grease, dairy, and meat flavor [18].

A total of 29 volatiles were assigned in the fermented juice with ethyl decanoate, phenylethanol, ethyl laurate, ethyl octanoate, hexanol, and ethyl acetate as main components. Remarkably, the total content of 1-nonanol, 3,6nonadien-1-ol, and nonanal was reduced from $51.68 \mathrm{mg} / \mathrm{L}$ in 


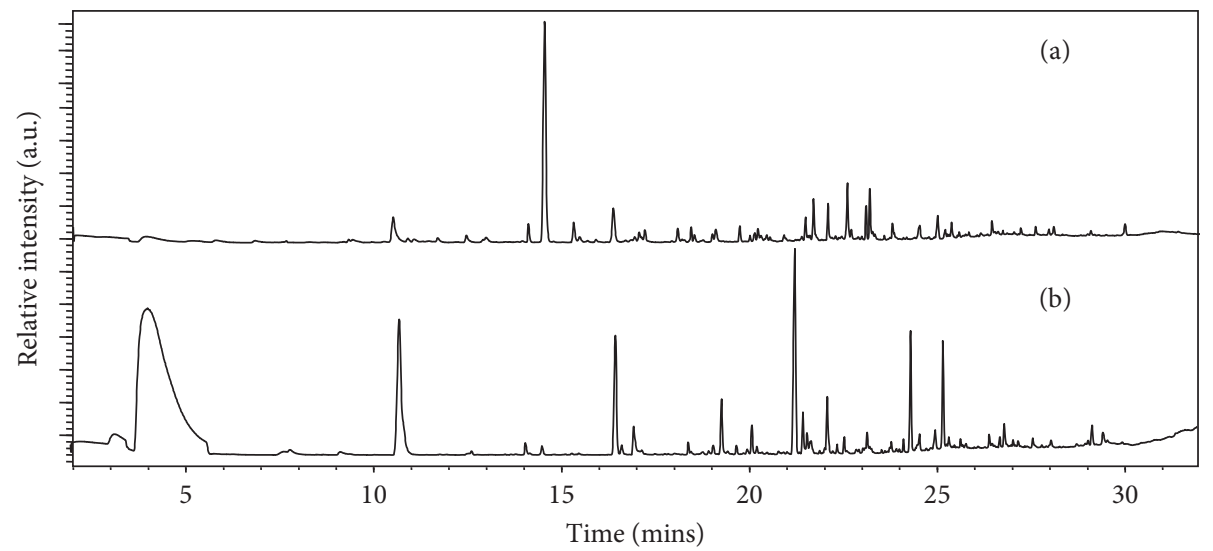

FIgURE 1: Total ionic chromatogram profiles of the unfermented juice (a) and fermented juice (b).

the unfermented juice to $26.41 \mathrm{mg} / \mathrm{L}$ in the fermented juice, while trans-2-nonenal and trans,cis-2,6-nonadienal were only detected in the unfermented juice. These volatiles possibly resulted from the physiological metabolism via the lipoxygenase pathway in the beginning stage or the subsequent fermentation [35]. Consequently, the content of the typical watermelon aroma was reduced from $92.08 \mathrm{mg} / \mathrm{L}$ in the unfermented juice to $26.41 \mathrm{mg} / \mathrm{L}$ in the fermented juice. Furthermore, a total of 14 esters were detected in the fermented juice with ethyl octanoate, ethyl acetate, and ethyl laurate as main components.

The volatiles of both unfermented juice and fermented juice are further classified based on their chemical structure and aroma style in Figure 2. Ester and alkane were main components of the fermented juice, while alcohol was the main component of the unfermented juice. Ester usually shows typical bouquet of grape wine, which is mainly formed during the fermentation $[9,22,36]$. Moreover, the acid and ester of the fermented juice were higher than that of the unfermented juice, while alcohol, aldehyde and ketone, and alkane of the fermented juice were lower than that of the unfermented juice. This phenomenon resulted from the formation of the acids and esters during the fermentation. Remarkably, isoamylol and ethyl octanoate were detected in the fermented juice, which induced the aroma of calvados and brandy. Hence, the fermented juice presented both typical watermelon and wine bouquet aroma.

The aroma of these volatiles was further classified as flower, fruit, grass, fragrant, oil, and bouquet based on their characteristic smells [18]. The bouquet and fragrant aromas of the fermented juice were stronger than that of the unfermented juice, while the other aroma was weaker than that of the unfermented juice. Combining the distribution of the chemical structure and aroma style of the volatiles, the bouquet of the fermented juice possibly originated from esters, while the fruits and flower mainly originated from alcohol, aldehyde and ketone, and alkane.

3.4. Sensory Evaluation of Unfermented and Fermented SeedWatermelon Juice. The sensory score of the unfermented and fermented juice was compared in Figure 3. The sensory score rated the intensity of appearance, flavor, sweetness, acidity, hotness, viscosity, and aroma in a nine-point category scale. The "1" in the nine-point category scale represented light or low, while the "9" represented full or high. Appearance includes properties such as color, reflectivity, transparency, self illumination, and texture [37]. The unfermented juice was cloudy with a light yellow, while the fermented juice was transparent with an attractive golden yellow. Moreover, the fermented juice was clearly reflective. Hence, the appearance score of the fermented juice was significantly higher than that of the unfermented juice, thus being more attractive for consumers.

The flavor of the fermented juice was statistically similar to that of the unfermented juice. The sweetness, acidity, and hotness were the main factors influencing the flavor. Specifically, both the sweetness and acidity of the fermented juice were significantly stronger than that of the unfermented juice. These experiences were in accordance with the results of the soluble solid content and titratable acid content, respectively. Very low level of hotness was present in the fermented juice, which was present in most alcoholic drinks. Therefore, the fermented juice would easily be accepted by most consumers.

Ten judges recognized strong watermelon aroma when the unfermented juice was approaching the booth, while 11 judges recognized the watermelon aroma of the fermented juice during the evaluation. Consequently, the aroma intensity of the fermented juice was significantly lower than that of the unfermented juice. This phenomenon was consistent with the content variation of the typical watermelon aroma content.

\section{Conclusion}

The DPPH, hydroxyl, and oxygen radical scavenging capacity of the fermented juice were stronger compared to those of the unfermented juice. The ORAC value of the fermented juice was $60 \mu \mathrm{M} \mathrm{TE} / \mathrm{g}$, which was $7.14 \%$ higher than that of the unfermented juice. GC-MS analysis showed a total of 26 and 29 volatiles the in unfermented and fermented juice, respectively. The content of the 
TABle 3: Volatiles of the unfermented and fermented juice.

\begin{tabular}{|c|c|c|c|c|c|}
\hline Type & Assigned compounds & Aroma & Classification & $\begin{array}{c}\text { Unfermented } \\
\text { juice } \\
(\mathrm{mg} / \mathrm{L})\end{array}$ & $\begin{array}{c}\text { Fermented } \\
\text { juice } \\
(\mathrm{mg} / \mathrm{L})\end{array}$ \\
\hline \multirow{15}{*}{ Esters } & Ethyl acetate & Bouquet with a light fruit smell & Fruit, fragrant, bouquet & - & $21.3 \pm 1.58$ \\
\hline & Isoamyl acetate & Banana-like aroma & Fruit & - & $13.0 \pm 0.67$ \\
\hline & Ethyl octanoate & Brandy aroma with sweet smell & Bouquet, fragrant & - & $30.5 \pm 2.32$ \\
\hline & Heptyl formate & Fruit and flower smell & Fruit, flower, oil & - & $11.0 \pm 1.02$ \\
\hline & Ethyl nonanoate & Fruit and brandy-like aroma & Oil, fruit, bouquet & - & $2.42 \pm 0.36$ \\
\hline & $\begin{array}{l}\text { 2-Methylpropyl } \\
\text { octanoate }\end{array}$ & - & - & - & $0.91 \pm 0.05$ \\
\hline & Ethyl decanoate & Coconut aroma & Fruit & - & $65.8 \pm 2.81$ \\
\hline & Ethyl undecanoate & Bouquet, oil, fruit & Bouquet, oil, fruit & - & $1.23 \pm 0.24$ \\
\hline & Phenethyl acetate & Sweet aroma & Fragment & - & $1.01 \pm 0.2$ \\
\hline & Ethyl laurate & Fragment and fruit & Fragment, fruit & - & $35.4 \pm 1.55$ \\
\hline & $\begin{array}{l}\text { 3-Methylbutyl } \\
\text { decanoate }\end{array}$ & - & - & - & $5.46 \pm 0.84$ \\
\hline & Ethyl myristate & $\begin{array}{l}\text { Coconut and iris-like aroma, } \\
\text { sweetness }\end{array}$ & Fruit, fragment & - & $11.7 \pm 0.87$ \\
\hline & Ethyl pentadecanoate & - & - & - & $0.61 \pm 0.05$ \\
\hline & Ethyl palmitoleate & Fruit and cream aroma & Fruit, oil & - & $4.34 \pm 1.21$ \\
\hline & & Subtotal & & 0 & 174.18 \\
\hline \multirow{19}{*}{ Alcohols } & Isobutanol & Grape wine smell & Bouquet & - & $2.73 \pm 0.24$ \\
\hline & Isoamylol & Calvados aroma and spicy & Bouquet & $8.27 \pm 1.25$ & $17.3 \pm 1.10^{*}$ \\
\hline & Hexanol & Grass, fragment, fruit, and oil & $\begin{array}{l}\text { Grass, fragment, fruit, } \\
\text { oil }\end{array}$ & $74.2 \pm 7.64$ & $22.1 \pm 0.87^{*}$ \\
\hline & 2,3-Butanediol & - & - & - & $1.07 \pm 0.09$ \\
\hline & Octanol & Fruit, flower, and grass & Fruit, flower, grass & $8.06 \pm 1.55$ & $11.9 \pm 1.17^{*}$ \\
\hline & 1-Methoxy-2-butanol & - & - & - & $0.91 \pm 0.04$ \\
\hline & 1-Nonanol & Watermelon-like aroma & Flower, fruit & $24.13 \pm 2.31$ & $14.8 \pm 0.87^{*}$ \\
\hline & 3,6-Nonadien-1-ol & Watermelon-like aroma & Fruit & $14.65 \pm 1.02$ & $11.0 \pm 1.24^{*}$ \\
\hline & Phenylethanol & $\begin{array}{c}\text { Pleasant and lasting fragrance of } \\
\text { roses }\end{array}$ & Flower & - & $40.3 \pm 2.91$ \\
\hline & Tridecanol & - & - & $4.32 \pm 0.32$ & $3.54 \pm 0.23^{*}$ \\
\hline & Alaninol & - & - & $3.37 \pm 0.48$ & - \\
\hline & 3-Hexen-1-ol & Strong smell of grass and fresh tea & Grass & $14.4 \pm 1.24$ & - \\
\hline & trans-2-Hexen-1-ol & Fruit and grass & Fruit, grass & $1.54 \pm 0.09$ & - \\
\hline & 1-Octen-3-ol & Mushroom and mud-like aroma & Grass & $5.71 \pm 1.02$ & - \\
\hline & Heptanol & Citrus aroma & Fruit, oil & $6.53 \pm 1.45$ & - \\
\hline & 2-Ethylhexan-1-ol & Sweet and light fragrance & Flower & $8.44 \pm 2.52$ & - \\
\hline & Benzyl alcohol & Light flower aroma & Flower & $1.75 \pm 0.07$ & - \\
\hline & Nerolidol & - & - & $2.17 \pm 0.73$ & - \\
\hline & & Subtotal & & 177.54 & 125.65 \\
\hline \multirow{7}{*}{ Alkanes } & $\begin{array}{l}\text { 4-Vinyl-2- } \\
\text { methoxyphenol }\end{array}$ & Flower, bouquet, and fruit & Flower, bouquet, fruit & - & $0.41 \pm 0.02$ \\
\hline & $\begin{array}{l}\text { 1,3-Di-tert- } \\
\text { butylbenzene }\end{array}$ & - & - & $18.4 \pm 1.62$ & - \\
\hline & Tridec-1-yne & - & - & $2.86 \pm 0.21$ & - \\
\hline & $\beta$-Caryophyllene & Light clove fragrance & Flower & $5.37 \pm 1.24$ & $224 \pm 10.8^{*}$ \\
\hline & Valencene & Citrus aroma & Fruit & $5.77 \pm 0.88$ & - \\
\hline & 2,4-Di-tert-butylphenol & - & - & $6.87 \pm 0.79$ & - \\
\hline & & Subtotal & & 39.27 & 224.41 \\
\hline \multirow{7}{*}{$\begin{array}{l}\text { Aldehyde } \\
\text { and } \\
\text { ketones }\end{array}$} & Nonanal & $\begin{array}{c}\text { Watermelon } \\
\text { aroma, sweet } \\
\text { with beeswax flower } \\
\text { Watermelon and }\end{array}$ & Fruit, flower & $12.9 \pm 1.25$ & $0.61 \pm 0.02^{*}$ \\
\hline & trans-2-Nonenal & $\begin{array}{l}\text { cucumber } \\
\text {-like aroma }\end{array}$ & Fruit & $16.8 \pm 2.06$ & - \\
\hline & $\begin{array}{l}\text { trans,cis-2-6- } \\
\text { Nonadienal }\end{array}$ & $\begin{array}{l}\text { Watermelon- } \\
\text { like aroma }\end{array}$ & Fruit & $23.6 \pm 2.18$ & - \\
\hline & $\beta$-Cyclocitral & Fruit and flower & Fruit, flower & $8.38 \pm 1.38$ & - \\
\hline & $\beta$-Jonone & Violet aroma & Flower & $2.96 \pm 0.63$ & - \\
\hline & $\begin{array}{l}\text { 3-Hydroxy-2 } \\
\text {-oxobutane }\end{array}$ & Cream aroma & Oil & $6.09 \pm 1.24$ & - \\
\hline & & Subtotal & & 70.73 & 0.61 \\
\hline
\end{tabular}


TABLE 3: Continued.

\begin{tabular}{|c|c|c|c|c|c|}
\hline Type & Assigned compounds & Aroma & Classification & $\begin{array}{c}\text { Unfermented } \\
\text { juice } \\
(\mathrm{mg} / \mathrm{L})\end{array}$ & $\begin{array}{c}\text { Fermented } \\
\text { juice } \\
(\mathrm{mg} / \mathrm{L})\end{array}$ \\
\hline \multirow{4}{*}{ Acids } & Acetic acid & - & - & - & $6.72 \pm 1.54$ \\
\hline & Octanoate & Fruit & Fruit & $2.38 \pm 0.35$ & $5.36 \pm 2.08^{*}$ \\
\hline & Decanoic acid & - & - & - & $7.14 \pm 0.96$ \\
\hline & & Subtotal & & 2.38 & 19.22 \\
\hline
\end{tabular}

-, not detected or not found; ${ }^{*}$ a significant difference with data in the same line.

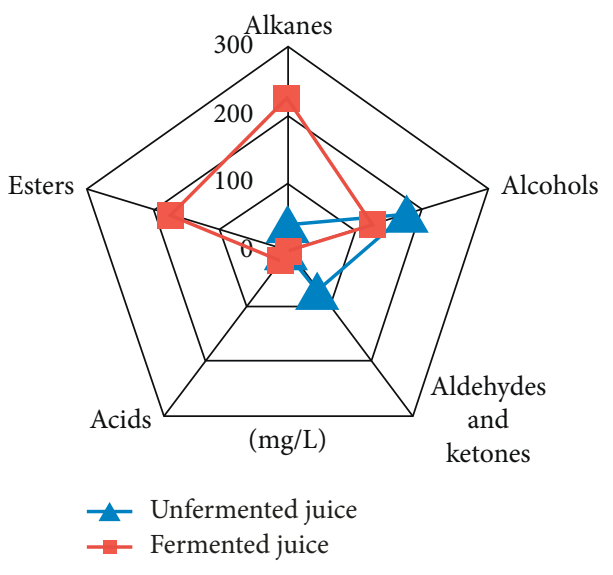

(a)

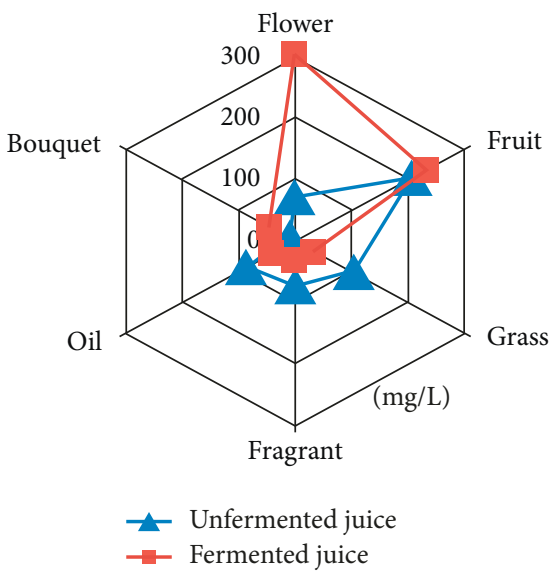

(b)

Figure 2: Volatile structure (a) and aroma style (b) distribution of the unfermented and fermented juice.

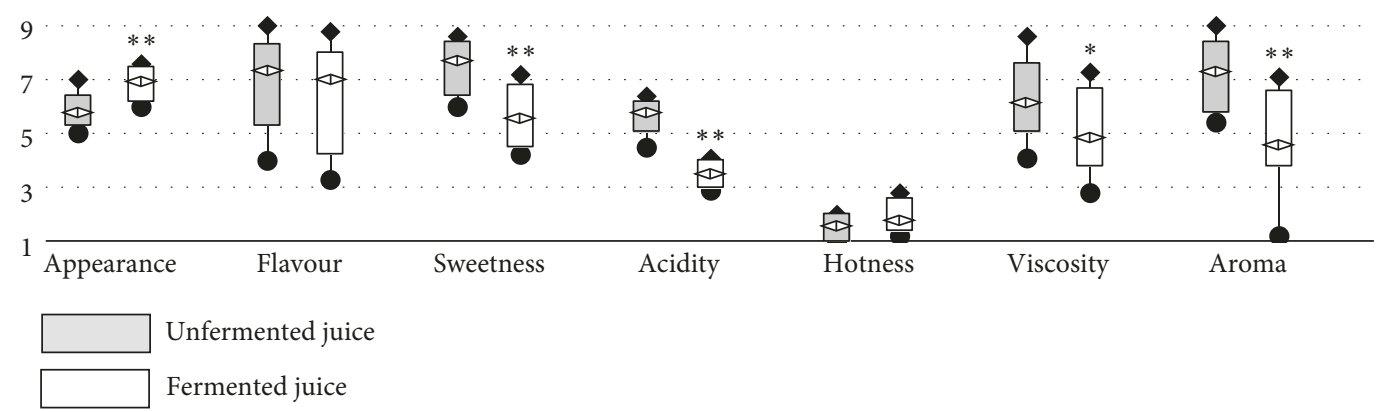

FIgURE 3: Sensory score of the unfermented and fermented juice. $\diamond$ is the maximum of the score; $\bullet$ is the minimum of the score; $\diamond$ is the mean of the score. The histogram is the distribution of the score except the maximum and the minimum. ${ }^{*}$ and ${ }^{* *}$ represent the significant difference between the mean of the unfermented juice and fermented juice at levels 0.05 and 0.01 , respectively.

typical watermelon aroma, including 1-nonanol, 3,6nonadien-1-ol, nonanal, trans-2-nonenal, and trans,cis2,6 -nonadienal, was reduced from $92.08 \mathrm{mg} / \mathrm{L}$ in the unfermented juice to $26.41 \mathrm{mg} / \mathrm{L}$ in the fermented juice. Furthermore, isoamylol, ethyl octanoate, ethyl acetate, and ethyl laurate contributed the typical grape-wine bouquet to the fermented juice. The sensory evaluation further verified the results of the characterization. The fermented juice presented an attractive appearance and watermelon aroma. Therefore, the fermented seedwatermelon juice showed a strong radical scavenging capacity and presented the typical watermelon aroma with a grape-wine bouquet.

\section{Data Availability}

The data used to support the findings of this study are available from the corresponding author upon request.

\section{Conflicts of Interest}

The authors declare that they have no conflicts of interest.

\section{Acknowledgments}

The authors are grateful to financial support of China Agricultural Research System (CARS-25), Beijing Municipal 
Natural Science Foundation (6172013), Beijing Academy of Agricultural and Forestry Sciences Youth Funds (QNJJ201802), and Beijing Advanced Innovation Center for Food Nutrition and Human Health Open Funds (20181053).

\section{Supplementary Materials}

Specifically, the data of Table 3 are listed in the "Volatile" sheet; the data of Figure 2 are listed in the "Volatile distributions" sheet; the original data of Table 1 are listed in the "DPPH" and "OH" sheet; the original data of Table 2 are listed in the "ORAC" sheet. (Supplementary Materials)

\section{References}

[1] S. Altaş, G. Kızıl, M. Kızıl, A. Ketani, and P. I. Haris, "Protective effect of Diyarbakır watermelon juice on carbon tetrachloride-induced toxicity in rats," Food and Chemical Toxicology, vol. 49, no. 9, pp. 2433-2438, 2011.

[2] A. J. Edwards, B. T. Vinyard, E. R. Wiley et al., "Consumption of watermelon juice increases plasma concentrations of lycopene and $\beta$-carotene in humans," Journal of Nutrition, vol. 133, no. 4, pp. 1043-1050, 2003.

[3] A. Rahmat, R. Rosli, W. N. I. W. M. Zain, S. Endrini, and H. A. Sani, "Antiproliferative activity of pure lycopene compared to both extracted lycopene and juices from watermelon (Citrullus vulgaris) and papaya (Carica papaya) on human breast and liver cancer cell lines," Journal of Medical Sciences, vol. 2, pp. 55-58, 2002.

[4] J. Zhang, "Breeding and production of watermelon for edible seed in China," Cucurbit Genetics Cooperative Report, vol. 19, pp. 66-67, 1996.

[5] C. Guo, J. Yang, J. Wei, Y. Li, J. Xu, and Y. Jiang, "Antioxidant activities of peel, pulp and seed fractions of common fruits as determined by FRAP assay," Nutrition Research, vol. 23, no. 12, pp. 1719-1726, 2003.

[6] A. C. C. Egbuonu, "Assessment of some antinutrient properties of the watermelon (Citrullus lanatus) rind and seed," Research Journal of Environmental Sciences, vol. 9, no. 5, pp. 225-232, 2015.

[7] G. V. Jones and K. H. Storchmann, "Wine market prices and investment under uncertainty: an econometric model for Bordeaux Crus Classés," Agricultural Economics, vol. 26, no. 2, pp. 115-133, 2001.

[8] C. Sánchez-Morenoa, A. J. Larraurib, and F. Saura-Calixto, "Free radical scavenging capacity and inhibition of lipid oxidation of wines, grape juices and related polyphenolic constituents," Food Research International, vol. 32, no. 6, pp. 407-412, 1999.

[9] H. Wasila, X. Li, L. Liu, I. Ahmad, and S. Ahmad, "Peel effects on phenolic composition, antioxidant activity, and making of pomegranate juice and wine," Journal of Food Science, vol. 78, no. 8, pp. C1166-C1172, 2013.

[10] J. Marais, "Terpenes in the aroma of grapes and wines: a review," South African Journal of Enology and Viticulture, vol. 4, no. 2, pp. 49-58, 2017.

[11] Y. Yang, Y. Xia, X. Lin et al., "Improvement of flavor profiles in Chinese rice wine by creating fermenting yeast with superior ethanol tolerance and fermentation activity," Food Research International, vol. 108, pp. 83-92, 2018.

[12] C. Zhang, X. Deng, Y. Ma, X. Zhao, and W. Li, "Effect of fermented strains on aroma of the seed-watermelon wine,"
Food Industry and Tecnoolgy, vol. 37, pp. 241-246, 2016, in Chinese.

[13] L. Yu, J. Perret, M. Harris, J. Wilson, and S. Haley, "Antioxidant properties of bran extracts from "Akron" wheat grown at different locations," Journal of Agricultural and Food Chemistry, vol. 51, no. 6, pp. 1566-1570, 2003.

[14] L. Yu, S. Haley, J. Perret, M. Harris, J. Wilson, and M. Qian, "Free radical scavenging properties of wheat extracts," Journal of Agricultural and Food Chemistry, vol. 50, no. 6, pp. 16191624, 2002.

[15] H. L. Madsen, B. R. Nielsen, G. Bertelsen, and L. H. Skibsted, "Screening of antioxidative activity of spices, a comparison between assays based on ESR spin trapping and electrochemical measurement of oxygen consumption," Food Chemistry, vol. 57, no. 2, pp. 331-337, 1996.

[16] B. Ou, D. Huang, M. Hampsch-Woodill, J. A. Flanagan, and E. K. Deemer, "Analysis of antioxidant activities of common vegetables employing oxygen radical absorbance capacity (ORAC) and ferric reducing antioxidant power (FRAP) assays: a comparative study," Journal of Agricultural and Food Chemistry, vol. 50, no. 11, pp. 3122-3128, 2002.

[17] K. Zhou and L. Yu, "Effects of sextraction solvent on wheat bran antioxidant activity estimation," LWT-Food Science and Technology, vol. 37, no. 7, pp. 717-721, 2004.

[18] R. Croteau and F. Karp, Perfumes, Springer, Dordrecht, Netherlands, 1994.

[19] K. Marsh, S. Attanayake, S. Walker, A. Gunson, H. Boldingh, and E. Macrae, "Acidity and taste in kiwifruit," Postharvest Biology and Technology, vol. 32, no. 2, pp. 159-168, 2004.

[20] USDA, United States Standanrds for Grades of Orange Juice, Processed Products Branch, Agricultural Marketing Service, Department of Agriculture, Washington, DC, USA, 1983.

[21] K. M. Yoo, M. Al-Farsi, H. Lee, H. Yoon, and C. Y. Lee, "Antiproliferative effects of cherry juice and wine in Chinese hamster lung fibroblast cells and their phenolic constituents and antioxidant activities," Food Chemistry, vol. 123, no. 3, pp. 734-740, 2010.

[22] J. Burns, P. T. Gardner, D. Matthews, G. G. Duthie, J. Lean, and A. Crozier, "Extraction of phenolics and changes in antioxidant activity of red wines during vinification," Journal of Agricultural and Food Chemistry, vol. 49, no. 12, pp. 5797-5808, 2001.

[23] L. Bravo, "Polyphenols: chemistry, dietary sources, metabolism, and nutritional significance," Nutrition Reviews, vol. 56, pp. 317-333, 1998.

[24] D. Villano, M. S. Fernández-Pachón, M. L. Moyá, A. M. Troncoso, and M. C. García-Parrilla, "Radical scavenging ability of polyphenolic compounds towards DPPH free radical," Talanta, vol. 71, no. 1, pp. 230-235, 2007.

[25] Q. Gui and Y. Zhang, "Preparation and antioxidant activity of the coconut wine," Food Indusrty, vol. 36, pp. 44-46, 2004, in Chinese.

[26] N. J. Temple, "Antioxidants and disease: more questions than answers," Nutrition Research, vol. 20, no. 3, pp. 449-459, 2000.

[27] L. K. Wolfe and R. H. Liu, "Cellular antioxidant activity (CAA) assay for assessing antioxidants, foods, and dietary supplements," Journal of Agricultural and Food Chemistry, vol. 55, no. 22, pp. 8896-8907, 2007.

[28] Y. Wang, W. Li, Y. Ma, X. Zhao, and C. Zhang, "Effect of thermal treatments on quality and aroma of watermelon juice," Journal of Food Quality, vol. 2018, Article ID 9242675, 7 pages, 2018.

[29] A. Dávalos, B. Bartolomé, and C. Gómez-Cordovés, "Antioxidant properties of commercial grape juices and vinegars," Food Chemistry, vol. 93, no. 2, pp. 325-330, 2005. 
[30] A. A. Williams and P. R. Rosser, "Aroma enhancing effects of ethanol,” Chemical Senses, vol. 6, no. 2, pp. 149-153, 1981.

[31] J. A. Pino, R. Marbot, and J. Aguero, "Volatile components of watermelon (Citrullus Ianatus [Thunb.] Matsum. et Nakai) fruit," Journal of Essential Oil Research, vol. 15, no. 6, pp. 379-380, 2003.

[32] J. C. Beaulieu and J. M. Lea, "Characterization and semiquantitative analysis of volatiles in seedless watermelon varieties using solid-phase microextraction," Journal of Agricultural and food Chemistry, vol. 54, no. 20, pp. 77897793, 2006.

[33] X. Tang, H. He, Y. Liu, and X. Zhao, "Identification of aroma compounds in watermelon juice by SPME-GCMS," Acta Horticulturae, vol. 944, pp. 183-191, 2012.

[34] Y. Wang, X. Guo, Y. Ma, X. Zhao, and C. Zhang, "Effect of ultra-high temperature treatment on qualities of watermelon juice," Food Science and Nutrition, vol. 6, no. 3, pp. 594-601, 2018.

[35] B. Zhang, X. R. Yin, X. Li, S. L. Yang, I. B. Ferguson, and K. S. Chen, "Lipoxygenase gene expression in ripening kiwifruit in relation to ethylene and aroma production," Journal of Agricultural and Food Chemistry, vol. 57, no. 7, pp. 2875-2881, 2009.

[36] E. Kafkas, T. Cabaroglu, S. Selli et al., "Identification of volatile aroma compounds of strawberry wine using solid-phase microextraction techniques coupled with gas chromatography-mass spectrometry," Flavour and Fragrance Journal, vol. 21, no. 1, pp. 68-71, 2006.

[37] M. L. G. M. Martin, W. Ji, R. Luo, J. Hutchings, and F. J. Heredia, "Measuring colour appearance of red wines," Food Quality and Preference, vol. 18, no. 6, pp. 862-871, 2007. 


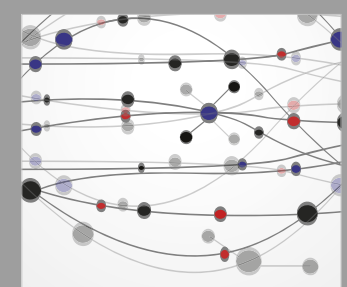

The Scientific World Journal
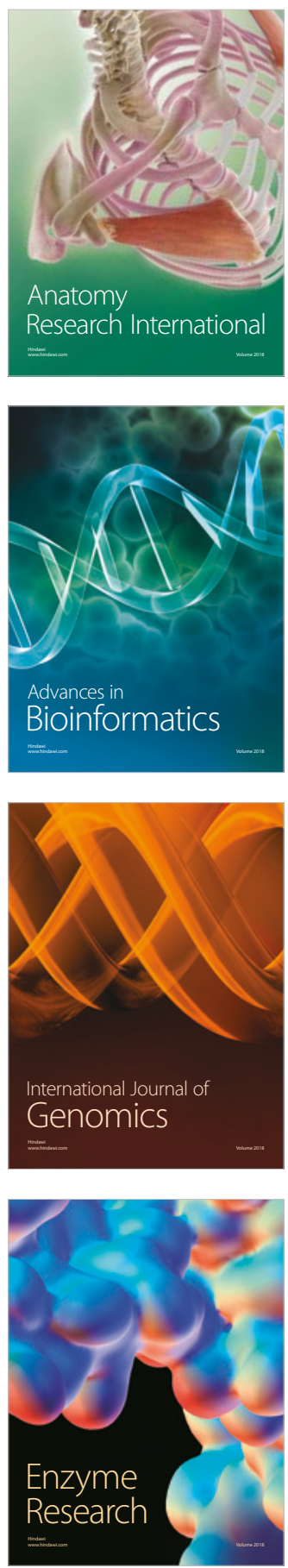
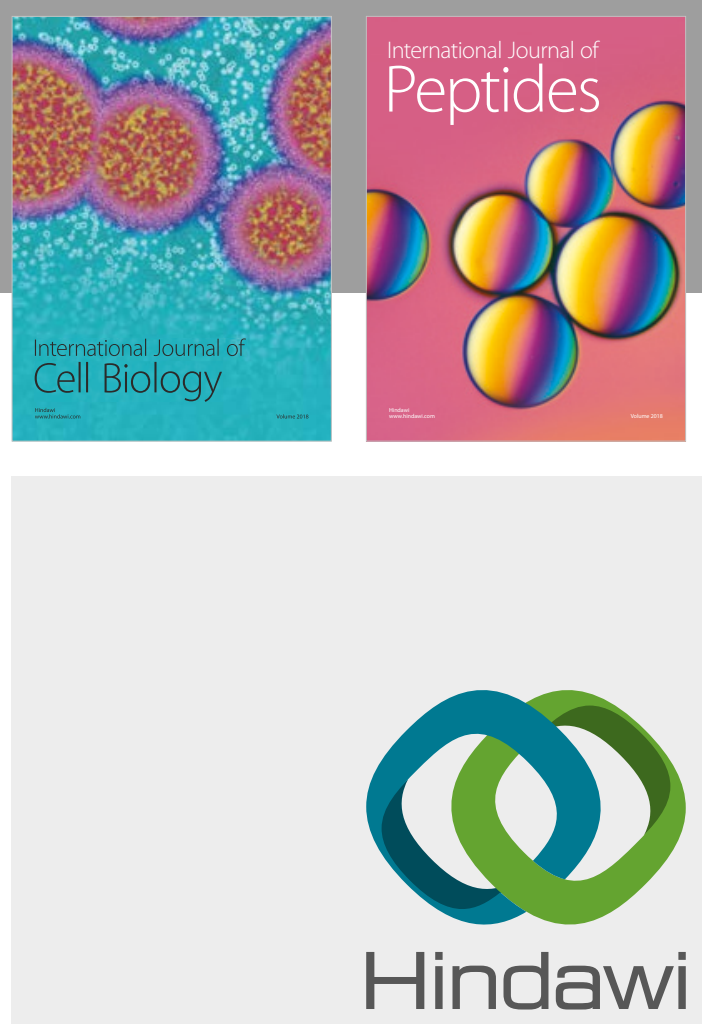

Submit your manuscripts at

www.hindawi.com
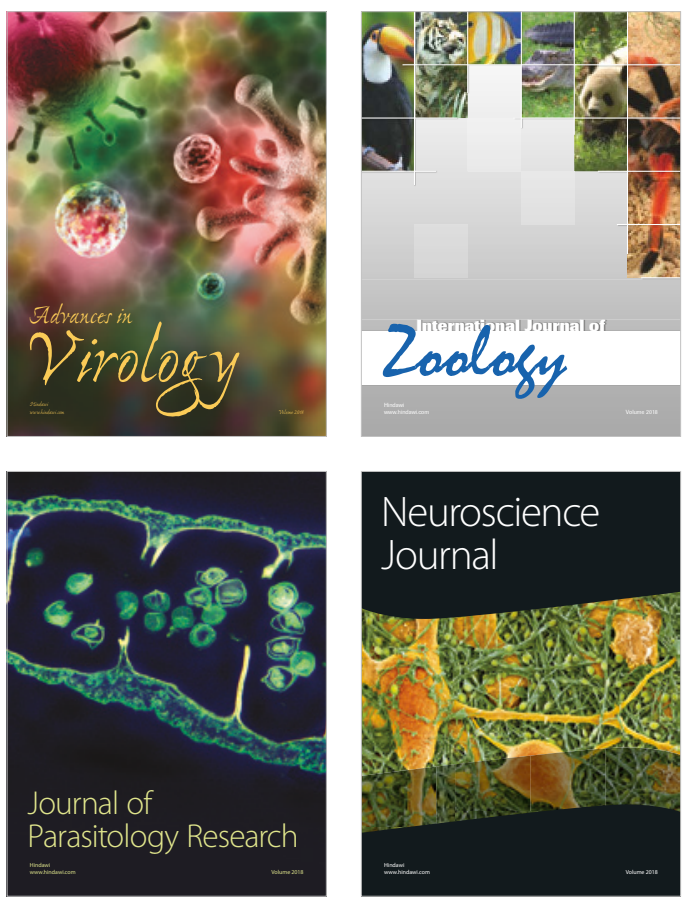
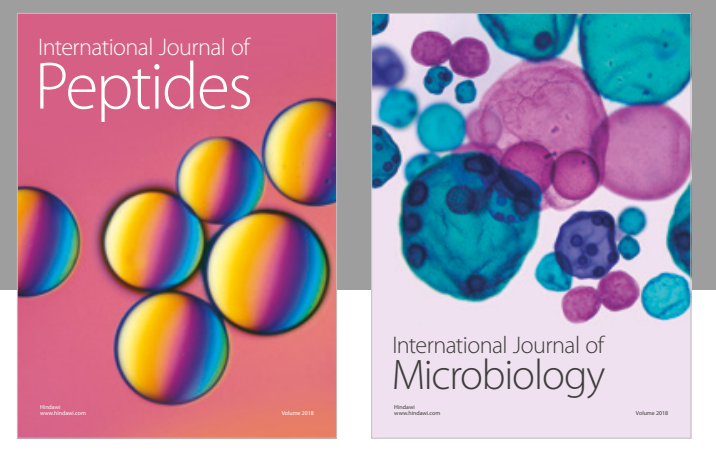

nternational Journal of Microbiology
Journal of
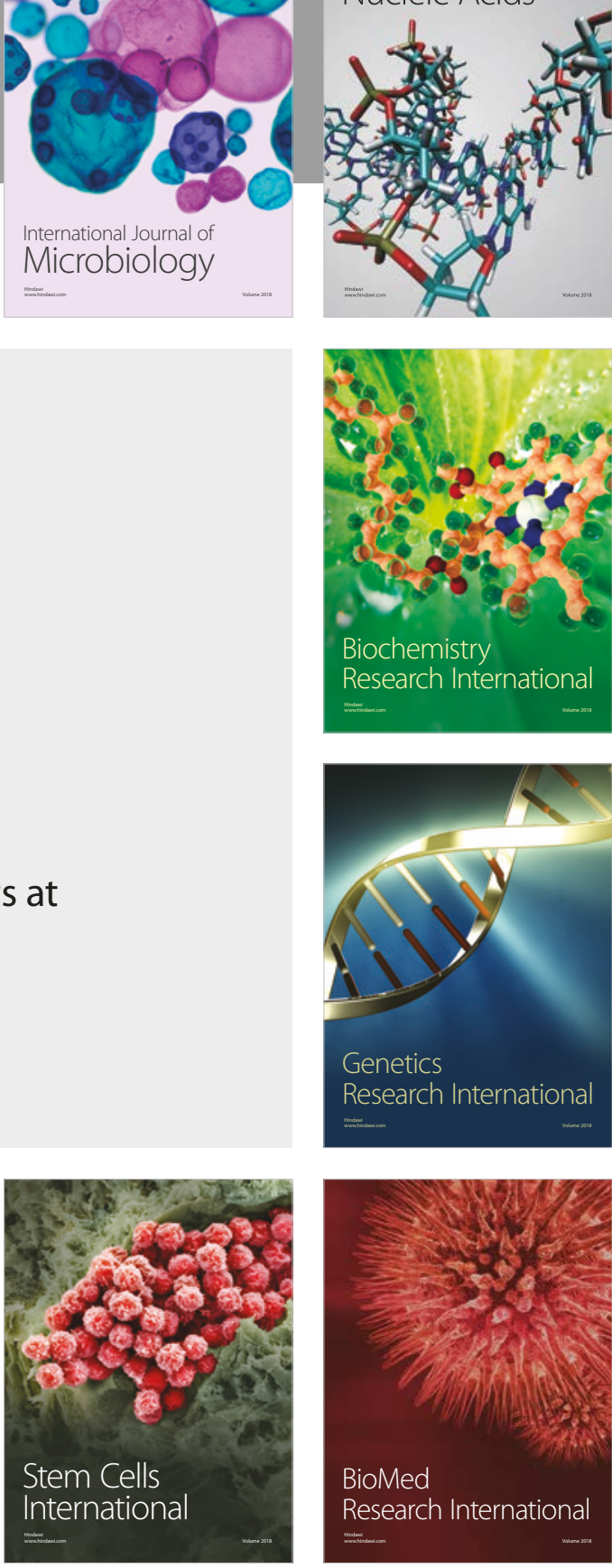
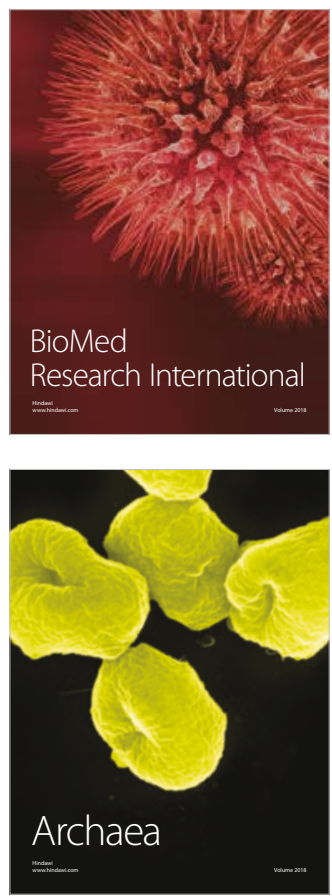